\title{
Morita-Baylis-Hillman Reaction with 7-Chloroquinoline Derivatives-New Compounds with Potential Anticancer Activity
}

\author{
João Paulo G. Oliveira, ${ }^{a}$ Guilherme S. Caleffi, ${ }^{\oplus a}$ Everton P. Silva, ${ }^{a}$ Maísa C. Coelho, ${ }^{a}$ Aleff C. Castro, ${ }^{\circledR a}$ \\ Rhuan K. S. Mendes, ${ }^{a}$ Tayná R. Olegário, ${ }^{a}$ Claudio G. Lima-Junior, ${ }^{\oplus * a}$ Mario L. A. A. Vasconcellos, ${ }^{a}$ \\ Júlia L. C. Souza, ${ }^{b}$ Sílvia M. Souza, ${ }^{b}$ Gardênia C. G. Militão, ${ }^{b}$ Boniek G. Vaz ${ }^{\circledR c}$ and Ruver R. F. Ramalho ${ }^{c}$
}

\author{
${ }^{a}$ Laboratório de Síntese da Química Orgânica Medicinal da Paraíba (LASOM-PB), \\ Departamento de Química, Universidade Federal da Paraíba, 58051-900 João Pessoa-PB, Brazil \\ ${ }^{b}$ Departamento de Fisiologia e Farmacologia, Universidade Federal de Pernambuco, \\ 50670-901 Recife-PE, Brazil \\ 'Instituto de Química, Universidade Federal de Goiás, Campus Samambaia, \\ 74690-900 Goiânia-GO, Brazil
}

\begin{abstract}
Morita-Baylis-Hillman adducts (MBHA) is a class of polyfunctional molecules that has been standing out due to their versatility and expressive biological activities. Therefore, this paper describes the synthesis and antiproliferative activity of some new MBHA/7-choroquinoline hybrids. The Michael acceptors were obtained starting from 4,7-dichloroquinoline which were submitted to the Morita-Baylis-Hillman reaction with ortho, meta and para-nitrobenzaldehyde. The in vitro screening of the synthetized MBHA against NCI-H292, HCT-116 and MCF-7 cancer cells suggests the influence of the spacer chain in its inhibition potential. The $50 \%$ inhibitory concentration $\left(\mathrm{IC}_{50}\right)$ obtained in the antiproliferative assay using MCF-7, HCT-116, HL-60 and NCI-H292 cancer cells indicate expressive cytotoxic potential of the adducts containing nitro group in the ortho position, with $\mathrm{IC}_{50}$ of $4.60 \mu \mathrm{mol} \mathrm{L}{ }^{-1}$. MBHA/7-choroquinoline hybrids were more active than MBHA described in literature, indicating the improvement of the cytotoxic effect due to 7-chloroquinoline moiety in the molecular structure, with maximum selectivity index values of 11.89 .
\end{abstract}

Keywords: antiproliferative activity, Morita-Baylis-Hillman adducts, 4,7-dichloroquinoline, nitrobenzaldehydes, $\mathrm{C}-\mathrm{C}$ bond

\section{Introduction}

Cancer is a generic word for a group of diseases that cause disordered growth of cells. It is the second cause of death in the world, causing about 10 million deaths in 2018. Some examples of the most common cancer are colorectal, breast and lung cancer. ${ }^{1}$

Cancer can be initiated by intrinsic factors or factors external to the body that lead to genetic changes. Tumor development can occur anywhere in the body and spread beyond its place of origin through the process known as metastasis, making it difficult to treat the disease. ${ }^{1,2}$

The increase in the incidence of various types of cancer creates a need for new anticancer drugs. For example, 1.7 million of new cancer cases and 606,880 cancer deaths were projected to occur in 2019 in the United States. ${ }^{3}$

*e-mail: claudio@quimica.ufpb.br
Quinolines belong to an important class of heterocycles, and have derivatives with interesting biological activities. ${ }^{4}$ Quinoline core containing compounds are studied because of their demonstrated inhibition activity of protein kinases and inhibition of cell growth and interaction with the growth factor receptor. ${ }^{5}$ Derivatives of the 7-chloroquinoline nucleus have been studied in recent years as candidates for various activities such as antitumor, leishmanicidal, antinociceptive and anti-inflammatory activities, antituberculosis and antizika virus. ${ }^{6-11}$

Hybridization of this nucleus with other groups may increase its activity, since hybrid molecules may have double or multiple actions, depending on the different pharmacophoric units linked to a single chemical entity. Moreover, the potential advantages of this strategy include lower effective therapeutic doses and the reduction of drug resistance. ${ }^{12}$

One way to hybridize chemical groups is through the 
Morita-Baylis-Hillman reaction (MBHR). This reaction consists in the formation of a $\mathrm{C}-\mathrm{C}$ bond between two groups, efficiently and with total economy of atoms. ${ }^{13,14}$ Morita-Baylis-Hillman adducts (MBHA) are considered a class of molecules with good cytotoxic potential for various diseases, being efficiently produced by the MBHR. ${ }^{15-19}$

The nitro benzaldehyde group was used in MBHR with 7-chloroquinoline derivatives as Michael acceptors aiming to enhance its activity according to Figure 1 . This proposal is based on previous studies ${ }^{15}$ performed by our research group that showed excellent results of several biological activities of the MBHA based on nitrobenzaldehyde derivatives.

Inspired by the biological profile of 7-chloroquinoline and its importance in pharmaceutical and biological fields, it was thought worthwhile the development of new molecules based on 7-chloroquinoline with a view to obtain new chemical entities with enhanced activity. Due to this context, this paper describes the synthesis and antiproliferative activity evaluation of new MBHA based on 7-chloroquinoline moiety.

\section{Experimental}

\section{General}

All commercially available reagents were used without further purification. Reactions were monitored by thin-layer chromatography (TLC) using Silica gel 60 UV254 pre-coated silica gel plates (Macherey-Nagel, Düren, Germany). Flash column chromatography was performed on a silica gel (300-400 mesh) using an ethyl acetate (Vetec, Rio de Janeiro, Brazil) and hexane (Vetec, Rio de Janeiro, Brazil) mixture as eluent. Fourier transform infrared (FTIR) spectra were recorded on a Shimadzu IR Prestige-21 spectrophotometer. Hydrogen-nuclear magnetic resonance ( ${ }^{1} \mathrm{H}$ NMR) spectra were recorded in dimethyl sulfoxide<smiles>C=C(C(=O)OC)C(O)c1ccccc1[N+](=O)[O-]</smiles>

$\mathrm{IC}_{50}=45.7 \mu \mathrm{M}(\mathrm{HL}-60$ cells $)$<smiles>COc1ccnc2cc(Cl)ccc12</smiles>

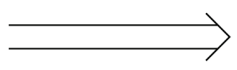

7-chloroquinoline nucleus
(DMSO- $d_{6}$ ) or $\mathrm{CDCl}_{3}$ (Cambridge Isotope Laboratories, Tewksbury, USA) with a Varian Mercury Spectra AC 20 or Bruker Avance II (500, 400 or $200 \mathrm{MHz}$ for $\left.{ }^{1} \mathrm{H}\right)$. Chemical shift $(\delta)$ values are expressed as parts per million (ppm) downfield from tetramethylsilane (TMS; $\delta 0.00 \mathrm{ppm}$ ) with $J$ values in hertz. Splitting patterns are indicated as $\mathrm{s}$ : singlet, d: doublet, t: triplet, q: quartet, m: multiplet, dd: double doublet, ddd: doublet of doublets of doublets, and br: broad peak. Carbon-nuclear magnetic resonance $\left({ }^{13} \mathrm{C}\right.$ NMR) spectra were recorded in DMSO- $d_{6}$ or $\mathrm{CDCl}_{3}$ with a Varian Mercury Spectra AC 20 or Bruker Avance II $\left(126,101\right.$ or $50 \mathrm{MHz}$ for $\left.{ }^{13} \mathrm{C}\right)$ spectrometer and the chemical shifts are reported in the scale relative to $\mathrm{CDCl}_{3}$ and DMSO- $d_{6}$. Fourier transform mass spectrometry (FTMS) with probe electrospray ionization (pESI) was performed using a Bruker Compass DataAnalysis Software (Brucker Daltonics, Bremen, Germany).

Typical procedure for the synthesis of 7-chloroquinoline 4- substituted (2-4)

4,7-Dichloroquinoline (1) (3 mmol, 1 equiv.; SigmaAldrich, São Paulo, Brazil) and respective diol (36 mmol, 12 equiv.) were mixed at room temperature. It was added potassium $t$-butoxide $(4.5 \mathrm{mmol}, 1.5$ equiv.; SigmaAldrich, São Paulo, Brazil) and $t$-butanol (15 mL; SigmaAldrich, São Paulo, Brazil) and the flask was connected to a reflux condenser. The mixture was stirred at $80^{\circ} \mathrm{C}$ in oil bath for $18 \mathrm{~h} .{ }^{20} \mathrm{After}$ reaction completion as evidenced by TLC, the reaction mixture was quenched and it was added $15 \mathrm{~mL}$ of saturated solution of $\mathrm{NaHCO}_{3}$ (SigmaAldrich, São Paulo, Brazil). Then, it was extracted with dichloromethane $(3 \times 20 \mathrm{~mL}$; Vetec, Rio de Janeiro, Brazil) and the resulting organic phases were dried with anhydrous $\mathrm{Na}_{2} \mathrm{SO}_{4}$ (Sigma-Aldrich, São Paulo, Brazil). After filtration, the solvent was removed under reduced pressure to obtain the respective product (2-4) without further purification.

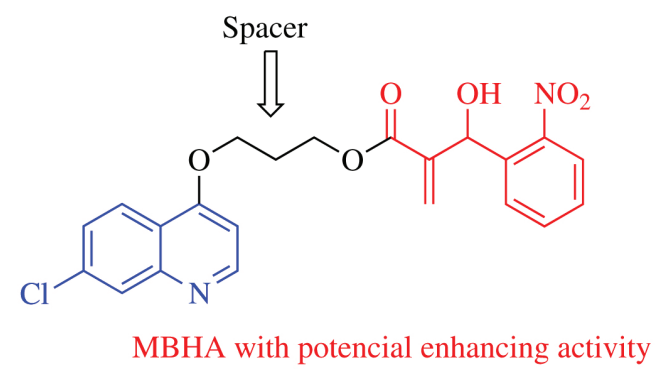

Figure 1. Design of structures based on the molecular hybridization. 
Typical procedure for the synthesis of intermediate compounds (2a-4a)

$1 \mathrm{mmol}$ of each derivative of 7-dichloroquinoline (2-4) was solubilized in $10 \mathrm{~mL}$ of dichloromethane and $5 \mathrm{mmol}$ of thionyl chloride $\left(\mathrm{SOCl}_{2}\right.$; Sigma-Aldrich, São Paulo, Brazil). The resulting mixture was stirred at reflux $45^{\circ} \mathrm{C}$ in oil bath for $16 \mathrm{~h}$. After reaction completion as evidenced by TLC, the reaction mixture was quenched with $20 \mathrm{~mL}$ of a saturated solution of $\mathrm{NaHCO}_{3}$. Then, it was extracted with dichloromethane $(3 \times 20 \mathrm{~mL})$ and the resulting organic phases were dried with anhydrous $\mathrm{Na}_{2} \mathrm{SO}_{4}$. After filtration, the solvent was removed under reduced pressure to obtain the respective product (2a-4a) without further purification.

Typical procedure for the synthesis of acrylates (5-7)

A solution of $1 \mathrm{mmol}$ of correspondent intermediate (2a-4a) and $1 \mathrm{mmol}$ of potassium acrylate (Sigma-Aldrich, São Paulo, Brazil) in N,N-dimethylformamide (DMF, $5 \mathrm{~mL}$; Sigma-Aldrich, São Paulo, Brazil) was stirred at reflux $160{ }^{\circ} \mathrm{C}$ in oil bath for $15 \mathrm{~h}$. After total conversion, evidenced by TLC, the reaction mixture was extracted with dichloromethane $(3 \times 20 \mathrm{~mL})$ and the resulting organic phases were dried with anhydrous $\mathrm{Na}_{2} \mathrm{SO}_{4}$. After filtration, the solvent was removed under reduced pressure to obtain the respective product (5-7) without further purification.

Typical procedure to MBHA derived from 7-chloroquinoline (5-7)

$0.5 \mathrm{mmol}$ of acrylate (5-7), $0.5 \mathrm{mmol}$ of nitrobenzaldehhyde and $0.5 \mathrm{mmol}$ of 1,4-diazabicyclo [2.2.2] octane (DABCO; Sigma-Aldrich, São Paulo, Brazil) were solubilized in $10 \mathrm{~mL}$ of $t$-butanol/water (9:1). The mixture was stirred at room temperature until conversion to the product. Total conversion was evidenced by TLC and the reaction mixture was extracted with dichloromethane $(2 \times 15 \mathrm{~mL})$. The resulting organic phases were dried with anhydrous sodium sulfate $\left(\mathrm{Na}_{2} \mathrm{SO}_{4}\right)$, filtered and the solvent was removed under reduced pressure. The products (8-16) were purified with flash chromatography using silica gel and ethyl acetate as eluent.

\section{In vitro cytotoxicity for cancer and normal cells}

The breast adenocarcinoma cell line ( $\mathrm{MCF}-7)$, mucoepidermoid pulmonary carcinoma cell line (NCI-H292), colon cancer cell line (HCT-116) and promyelocytic leukemia cell line (HL-60) were obtained from Rio de Janeiro Cell Bank (Rio de Janeiro, Brazil). In addition, human peripheral blood mononuclear cells (PBMCs) were obtained from healthy volunteers (approved by Human Research Ethics Committee of the Federal University of Pernambuco-Registration No. 66925717.2.0000.5208). The PBMCs were isolated according to the standard method of density gradient centrifugation over Ficoll Histopaque. The cells were maintained in Roswell Park Memorial Institute (RPMI) 1640 medium (Sigma-Aldrich, São Paulo, Brazil) or Dulbecco's modified eagle medium (DMEM) $\left(\right.$ Gigco $^{\mathrm{TM}}$ Life Technologies, Gaithersburg, USA) supplemented with $10 \%$ fetal bovine serum (Gigco ${ }^{\mathrm{TM}}$ Life Technologies, Gaithersburg, USA), 2 mM glutamine (Gigco ${ }^{\mathrm{TM}}$ Life Technologies, Gaithersburg, USA), $100 \mathrm{U} \mathrm{mL}^{-1}$ penicillin $\left(\right.$ Gigco $^{\mathrm{TM}}$ Life Technologies, Gaithersburg, USA), $100 \mu \mathrm{g} \mathrm{mL}^{-1}$ streptomycin (Gigco $^{\mathrm{TM}}$ Life Technologies, Gaithersburg, USA) at $37^{\circ} \mathrm{C}$ with $5 \% \mathrm{CO}_{2}$. PBMC were grown in supplemented RPMI-1640 medium plus 4\% phytohemagglutinin. To assess the cytotoxicity of the compounds, the 3-(4,5-dimethyl2-thiazolyl)-2,5-diphenyl-2 $H$-tetrazolium bromide (MTT; Sigma-Aldrich, St. Louis, USA) reduction assay was used after $72 \mathrm{~h}$ incubation. For all experiments, cells were plated in 96 -well plates $\left(10^{5}\right.$ cells $\mathrm{mL}^{-1}$ for adherent cells or $3 \times 10^{5}$ cells $\mathrm{mL}^{-1}$ for the leukemia and $10^{6}$ for PBMC). After $24 \mathrm{~h}$ the compounds were diluted $\left(50 \mu \mathrm{mol} \mathrm{L}{ }^{-1}\right)$ in medium with $0.5 \%$ dimethylsulfoxide (DMSO, Vetec, Rio de Janeiro, Brazil) and tumor cells were screened in triplicate at three different experiments.

The synthesized compounds were evaluated against tumor cells $\left(0.06-50 \mu \mathrm{mol} \mathrm{L} \mathrm{L}^{-1}\right)$ in order to obtain the concentration that causes $50 \%$ inhibition of cell growth $\left(\mathrm{IC}_{50}\right)$. Negative control received the same amount of DMSO. Doxorubicin (Sigma-Aldrich, St. Louis, USA) (0.01-5 $\left.\mu \mathrm{g} \mathrm{mL}^{-1}\right)$ was used as the positive control. After $69 \mathrm{~h}$ of treatment, $20 \mu \mathrm{L}$ of MTT (5 mg mL-1) was added. At the end of the incubation, the MTT formazan product was dissolved in $100 \mu \mathrm{L}$ of DMSO and the absorbance was measured at $595 \mathrm{~nm}$ in a plate spectrophotometer (Varioskan Flash; Thermo Fisher Scientific, Vantaa, Finland). After the preliminary study with a single concentration of $50 \mu \mathrm{mol} \mathrm{L} \mathrm{L}^{-1}$, the percentage of cell growth inhibition (mean and standard deviation) was calculated and only compounds with at least $75 \%$ inhibition in a cell line were considered active for the $\mathrm{IC}_{50}$ assay. $\mathrm{IC}_{50}$ values were calculated by non-linear regression with a $95 \%$ confidence interval.

\section{Results and Discussion}

\section{Chemistry}

7-Chloroquinoline alcohols derivatives were synthesized as shown in Figure 2. 4,7-Dichloroquinoline was subjected 
<smiles>Clc1ccc2c(Cl)ccnc2c1</smiles>

1<smiles>C=CC(=O)OCC(C)C</smiles><smiles>COc1ccnc2cc(Cl)ccc12</smiles>

(ii)

(iii)

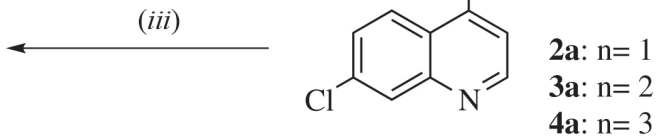

Figure 2. (i) Diol, $t$-butOK/t-butOH, $80^{\circ} \mathrm{C}, 18 \mathrm{~h}$ (94-97\%); (ii) $\mathrm{SOCl}_{2}, \mathrm{CH}_{2} \mathrm{Cl}_{2}, 45^{\circ} \mathrm{C}, 16 \mathrm{~h}(85 \%)$; (iii) potassium acrylate, DMF, reflux, $15 \mathrm{~h}$ (95-99\%).

to a nucleophilic aromatic substitution reaction $(i)$ with the corresponding diol under basic catalysis according to described in literature. ${ }^{20}$ The obtained products (2-4) were then subjected to a two steps reaction: (ii) the obtaining of the alkyl halides from alcohols and (iii) their esterification with potassium acrylate.

The conversion of alcohols to alkyl halides (2a-4a) was indicated by the absence of hydroxyl band in their respective FTIR spectra (see Supplementary Information section). The formation of acrylate was confirmed by ${ }^{1} \mathrm{H}$ NMR by the appearance of three double doublets for three vinyl hydrogen at 5.7-6.5 ppm.

Finally, the acrylates 5-7 were used as Michael acceptors in MBHR with ortho, meta or para-nitrobenzaldehyde, that are commercially available, according to the synthetic conditions given in Figure 3. DABCO was used as catalyst in the synthesis of the hybrids 8-16 whose yields are given in Table 1.

Although some of the synthesized molecules have been previously reported by our research group, ${ }^{12}$ most of the molecules reported in this research are novel to the best of our knowledge. These structures were elucidated by ${ }^{1} \mathrm{H}$ NMR, ${ }^{13} \mathrm{C}$ NMR and mass spectrometry. The ${ }^{13} \mathrm{C}$ NMR reveals the formation of the desired MBHA by the appearance of a carbinolic carbon at range 65-72 ppm in ${ }^{13} \mathrm{C}$ NMR. Moreover, the absence of one of three vinyl hydrogen in ${ }^{1} \mathrm{H}$ NMR reinforces the MBHA formation.
Table 1. Reaction time and yields of the new adducts 8-16 derivates of 7-chloroquinoline

\begin{tabular}{lcccccc}
\hline Compound & $\mathrm{n}$ & $\mathrm{R}_{1}$ & $\mathrm{R}_{2}$ & $\mathrm{R}_{3}$ & time /h & $\mathrm{Yield} / \%$ \\
\hline $\mathbf{8}$ & 1 & $\mathrm{NO}_{2}$ & $\mathrm{H}$ & $\mathrm{H}$ & 48 & 67 \\
$\mathbf{9}$ & 1 & $\mathrm{H}$ & $\mathrm{NO}_{2}$ & $\mathrm{H}$ & 24 & 71 \\
$\mathbf{1 0}$ & 1 & $\mathrm{H}$ & $\mathrm{H}$ & $\mathrm{NO}_{2}$ & 24 & 72 \\
$\mathbf{1 1}$ & 2 & $\mathrm{NO}_{2}$ & $\mathrm{H}$ & $\mathrm{H}$ & 168 & 43 \\
$\mathbf{1 3}$ & 2 & $\mathrm{H}$ & $\mathrm{NO}_{2}$ & $\mathrm{H}$ & 72 & 51 \\
$\mathbf{1 4}$ & 2 & $\mathrm{H}$ & $\mathrm{H}$ & $\mathrm{NO}_{2}$ & 120 & 74 \\
$\mathbf{1 6}$ & 3 & $\mathrm{NO}_{2}$ & $\mathrm{H}$ & $\mathrm{H}$ & 168 & 33 \\
\hline & 3 & $\mathrm{H}$ & $\mathrm{NO}_{2}$ & $\mathrm{H}$ & 120 & 41 \\
\hline
\end{tabular}

All spectral data were in accordance with the assumed structures.

In silico study

The evaluation of pharmacokinetic properties via theoretical studies is an important tool in the search for<smiles>C=CC(=O)OCCOc1ccnc2cc(Cl)ccc12</smiles>

$5-7$

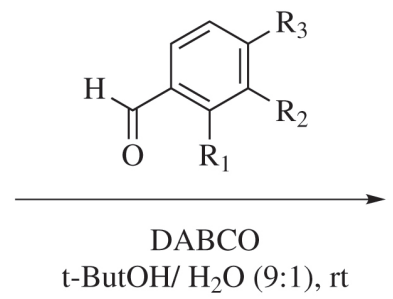

Figure 3. Reaction scheme and synthetic conditions of the new adducts 8-16 derivates of 7-chloroquinoline. 
new drug candidates, minimizing both the cost and the time required in the study. These attributes allow the use of in silico ADME (administration, distribution, metabolism and excretion) models in order to discern promising molecules from those with an unfavorable pharmacokinetic profile. ADME parameters provide important information about these properties, particularly about the absorption, which reflects directly on the bioavailability of the drug. ${ }^{21}$

One of the main studies for determining pharmacokinetic parameters based on physical-chemical properties is the Rule of Five, proposed by Lipinski et al..$^{22}$ Also called Lipinski's Rule, this rule establishes that the potential of a drug candidate is greater when the molecule meets at least three of the following conditions: molecular weight $\leq 500 \mathrm{~g} \mathrm{~mol}^{-1}$, number of hydrogen bond acceptors $\leq 10$ ( $\mathrm{N}$ or $\mathrm{O}$ atoms), number of hydrogen bond donors $\leq 5$ ( $\mathrm{NH}$ or $\mathrm{OH}$ groups) and $\log \mathrm{P} \leq 5$.

In addition to Lipinski's parameters, other physicochemical properties obtained via in silico studies have been explored by several research groups to predict the oral bioavailability of candidates to drugs. Veber et al..$^{23}$ proposes a simple approach based on the number of rotatable bonds and the topological polar surface area (TPSA) of the molecule to provide an effective rule for predicting drug absorption.

OSIRIS Property Explore ${ }^{24}$ and SwissADME ${ }^{25}$ software were used to obtain the physicochemical properties of the MBHAs proposed in this study. The calculated values are given in Table 2.
As expected, the data show that the compound's lipophilicity is directly influenced by the size of the spacer chain and the functional group/portion anchored to it. A brief comparison of cLog P between the classes of synthesized compounds allows us to verify that the alcohols (2-4) have a greater polarity in relation to the respective acrylated derivatives (5-7).

Variations in the size of the spacer chain in the synthesized MBHA has a direct influence on its lipophilicity, evidenced by the increase in the value of cLog P proportionally to the number of carbons in the chain. Taking the homologous MBHA $\mathbf{8}$ and $\mathbf{1 1}$ as an example, a variation of about 20\% in the value of cLog P can be observed. On the other hand, it is observed that the position of the substituent $-\mathrm{NO}_{2}$ in aromatics has practically no influence on the values of this parameter within the same series of molecules.

Regarding to the Rule of Five, it is possible to verify that all the evaluated molecules were within the limits established by Lipinski et al., ${ }^{22}$ and none of these parameters were exceeded, reinforcing the possible oral bioavailability of the compounds in question.

TPSA refers to the molecular surface area resulting from the summation of the tabulated surface contributions of the 2D polar fragments $(\mathrm{O}$ or $\mathrm{N}$ atoms and $\mathrm{H}$ atoms attached to them) ${ }^{26,27}$ It was found that the synthesized MBHA 8 to $\mathbf{1 6}$ showed a fixed TPSA value $\left(114.47 \AA^{2}\right)$, since their structural differences reside in the size of the spacer chain and in the position of the $-\mathrm{NO}_{2}$ group. As described in the literature, ${ }^{28}$ the percentage of absorption (ABS) is

Table 2. MBHA physicochemical properties obtained from OSIRIS Property Explorer ${ }^{24}$ and Swiss ADME software ${ }^{25}$

\begin{tabular}{lccccccccc}
\hline Compound & MW $/\left(\mathrm{g} \mathrm{mol}^{-1}\right)$ & HBD & HBA & cLog P & nV & RB & TPSA / $\AA^{2}$ & ABS / \% & DS \\
\hline $\mathbf{2}$ & 223.66 & 1 & 3 & 1.99 & 0 & 3 & 42.35 & 94.39 & 0.59 \\
$\mathbf{3}$ & 237.68 & 1 & 3 & 2.45 & 0 & 4 & 42.35 & 94.39 & 0.28 \\
$\mathbf{4}$ & 251.71 & 1 & 3 & 2.90 & 0 & 5 & 42.35 & 94.39 & 0.42 \\
$\mathbf{5}$ & 277.70 & 0 & 4 & 2.74 & 0 & 6 & 48.42 & 92.30 & 0.05 \\
$\mathbf{6}$ & 291.73 & 0 & 4 & 3.20 & 0 & 7 & 48.42 & 92.30 & 0.07 \\
$\mathbf{7}$ & 305.76 & 0 & 4 & 3.65 & 0 & 8 & 48.42 & 92.30 & 0.06 \\
$\mathbf{8}$ & 428.82 & 1 & 7 & 2.94 & 0 & 9 & 114.47 & 69.51 & 0.19 \\
$\mathbf{9}$ & 428.82 & 1 & 7 & 3.00 & 0 & 9 & 114.47 & 69.51 & 0.19 \\
$\mathbf{1 0}$ & 428.82 & 1 & 7 & 2.96 & 0 & 9 & 114.47 & 69.51 & 0.19 \\
$\mathbf{1 1}$ & 442.85 & 1 & 7 & 3.18 & 0 & 10 & 114.47 & 69.51 & 0.18 \\
$\mathbf{1 2}$ & 442.85 & 1 & 7 & 3.20 & 0 & 10 & 114.47 & 69.51 & 0.18 \\
$\mathbf{1 3}$ & 442.85 & 1 & 7 & 3.18 & 0 & 10 & 114.47 & 69.51 & 0.18 \\
$\mathbf{1 4}$ & 456.88 & 1 & 7 & 3.59 & 0 & 11 & 114.47 & 69.51 & 0.16 \\
$\mathbf{1 5}$ & 456.88 & 1 & 7 & 3.59 & 0 & 11 & 114.47 & 69.51 & 0.16 \\
$\mathbf{1 6}$ & 456.88 & 1 & 7 & 3.63 & 0 & 11 & 114.47 & 69.51 & 0.16 \\
\hline
\end{tabular}

MW: molecular weight; HBD: hydrogen bonding donor; HBA: hydrogen bonding acceptor; cLog P: octanol/water partition coefficient based on Molinspiration milog P model; nV: number of violations; RB: rotatable bonds; TPSA: topological polar surface area; ABS: absorption percentage; DS: drug score. 
closely linked to the value of TPSA, therefore all MBHA synthesized had the same value for this parameter $(69.51 \%)$.

Veber et al..$^{23}$ highlighted that molecules with TPSA values $\leq 140 \AA^{2}$ and rotatable bonds (RB) $\leq 10$ tend to have significant oral bioavailability. Among the proposed molecules, only adducts with a four-carbon spacer chain (14-16) do not simultaneously meet these conditions. As proposed by Zhao et al. ${ }^{28}$ in addition to Lipinski's parameters, these results indicate considerable capacity to penetrate the cell membrane.

Drug score (DS) indicates the overall potential of the compound to act as a drug and its calculation is based on the values of $\log$ P, $\log S$, druglikeness, molecular mass and risk of toxicity. It was possible to verify that the DS values calculated in this study were very close to each other. We highlight 8-10 adducts, considering that the probability of a compound to be bioactive is greater the closer to the unit is the DS value..$^{24,29}$

In vitro study

A single concentration screening of the molecules was performed aiming to identify the compounds with the highest inhibition potential against three cancer cells (NCI-H292, HCT-116 and MCF-7). After the preliminary assay, compounds with a percentage of inhibition greater than $75 \%$ were tested to determine their respective $\mathrm{IC}_{50}{ }^{30}$

The results presented in Table 3 are expressed as the mean of the inhibitory growth percentages (\%) followed by their respective standard deviations (SD). These data demonstrate that the synthetized alcohols 2-4 were not promising for the cancer cells evaluated, whereas one of the synthesized acrylates (5) showed inhibition superior to the reference drug, leading us to study its $\mathrm{IC}_{50}$.

Regarding the MBHA obtained, the derivatives showed better results as the spacer chain increased, demonstrating a possible influence of the lipophilicity on their inhibitory activity. We draw attention to the most lipophilic compounds (14-16), with a four-carbon spacer chain, as active as doxorubicin.

The antiproliferative activity of 7-chloroquinoline derivatives was evaluated investigating their effects on four cancer cell lines: MCF-7 (breast cancer), HCT-116 (colorectal cancer), HL-60 (promyelocytic leukemia) and NCI-H292 (lung cancer). Doxorubicin was used as a positive control. The results available in Table 4 are given as the mean of the $\mathrm{IC}_{50}$ values followed by their respective $\mathrm{SD}$.

The $\mathrm{IC}_{50}$ results demonstrate that nitro group at ortho position has a strong influence on the activity of the synthesized molecules, which was already expected
Table 3. Tumor cell growth inhibition (mean \pm SD) of compounds at a single concentration $\left(50 \mu \mathrm{mol} \mathrm{L}{ }^{-1}\right)$

\begin{tabular}{lccc}
\hline \multirow{2}{*}{ Compound } & \multicolumn{3}{c}{ Cell growth inhibition / \% } \\
\cline { 2 - 4 } $\mathbf{2}$ & NCI-H292 & HCT-116 & MCF-7 \\
$\mathbf{3}$ & 0 & $6.81 \pm 0.16$ & $42.00 \pm 3.54$ \\
$\mathbf{4}$ & 0 & $15.56 \pm 0.94$ & $46.17 \pm 0.92$ \\
$\mathbf{5}$ & $83.70 \pm 1.72$ & $80.02 \pm 6.30$ & $86.05 \pm 6.98$ \\
$\mathbf{6}$ & $74.00 \pm 5.00$ & $65.27 \pm 0.14$ & $48.10 \pm 2.74$ \\
$\mathbf{7}$ & 0 & $4.97 \pm 0.29$ & $26.26 \pm 2.58$ \\
$\mathbf{8}$ & $2.60 \pm 0.57$ & $27.19 \pm 0.77$ & $28.13 \pm 3.15$ \\
$\mathbf{9}$ & $77.70 \pm 10.90$ & $65.82 \pm 2.24$ & $55.40 \pm 1.97$ \\
$\mathbf{1 0}$ & 0 & $54.46 \pm 2.40$ & $46.36 \pm 7.79$ \\
$\mathbf{1 1}$ & $89.70 \pm 6.60$ & $100.68 \pm 2.18$ & $72.04 \pm 1.18$ \\
$\mathbf{1 2}$ & $\mathrm{NT}$ & $52.17 \pm 0.32$ & $76.35 \pm 12.80$ \\
$\mathbf{1 3}$ & $79.38 \pm 5.43$ & $52.41 \pm 2.35$ & $43.65 \pm 4.21$ \\
$\mathbf{1 4}$ & $80.30 \pm 6.90$ & $95.42 \pm 5.63$ & $72.71 \pm 5.70$ \\
$\mathbf{1 5}$ & $83.86 \pm 1.16$ & $90.44 \pm 8.42$ & $61.09 \pm 0.90$ \\
$\mathbf{1 6}$ & $86.40 \pm 0.50$ & $94.33 \pm 5.11$ & $73.36 \pm 3.91$ \\
Doxorubicin & $86.80 \pm 3.30$ & $79.30 \pm 1.19$ & $80.30 \pm 2.10$ \\
\hline
\end{tabular}

NCI-H292: mucoepidermoid pulmonary carcinoma cell line; HCT-116: colon cancer cell line; MCF-7: breast adenocarcinoma cell line; NT: not tested.

compared to other results presented in the literature. ${ }^{16}$ Expressive results can be observed in the activity of compounds 11 and 14 against HL-60, when compared to the MBHA previously published by our group. These values indicate a positive effect of the 7-chloroquinoline moiety, ${ }^{15}$ increasing their cytotoxic activity.

Furthermore, comparing compounds with different spacers we can observe that $\mathbf{1 5}$ (with four carbons) had a better activity than $\mathbf{9}$ (with two carbons), possibly due its major conformational freedom. The tests performed showed that compound 14 showed better $\mathrm{IC}_{50}$ values for MCF-7 and NCI-H292 cells. In contrast, compound $\mathbf{1 6}$ had the best result for HCT-116 cells and compound $\mathbf{1 1}$ had the best result for HL-60 cells.

After the tests against cancer cells, the molecules with the best $\mathrm{IC}_{50}$ values had their selectivity evaluated in healthy cells, since one of the major obstacles of the chemotherapy treatment is related to the attack of the drug to these cells, causing complications in the treatment.

Selectivity index (SI) corresponds to the ratio between the respective $\mathrm{IC}_{50}$ values of the pure compound against healthy cells (peripheral blood mononuclear cells, PBMC) and the pure compound against the cancer cell line, so that an SI value less than 2.0 indicates possible toxicity of the drug candidate. ${ }^{31}$ Table 5 shows the obtained results, 
Table 4. Cytotoxic effect of the active compounds $\left(\mathrm{IC}_{50}\right.$ with $95 \%$ confidence interval) against cancer cell lines by MTT assay after $72 \mathrm{~h}$ of treatment

\begin{tabular}{lcccc}
\hline \multirow{2}{*}{ Compound } & \multicolumn{4}{c}{$\mathrm{IC}_{50}(\text { confidence interval })^{\mathrm{a}} /(\mu \mathrm{mol} \mathrm{L}-1)$} \\
\cline { 2 - 5 } $\mathbf{5}$ & MCF-7 & HCT-116 & NCI-H292 & HL-60 \\
$\mathbf{6}$ & $30.97(22.69-42.49)$ & $20.53(13.32-30.97)$ & $47.53(38.17-59.06)$ & $14.76(11.88-18.37)$ \\
$\mathbf{9}$ & $\mathrm{NT}$ & $35.65(23.99-53.13)$ & $>50$ & $36.85(22.18-61.26)$ \\
$\mathbf{1 1}$ & $37.52(29.52-47.71)$ & $\mathrm{NT}$ & $25.42(22.15-28.68)$ & $12.36(6.76-22.85)$ \\
$\mathbf{1 2}$ & $36.04(23.48-54.19)$ & $17.82(10.16-31.16)$ & $13.32(11.52-15.36)$ & $5.06(3.88-6.59)$ \\
$\mathbf{1 3}$ & $41.14(35.32-47.96)$ & $\mathrm{NT}$ & $\mathrm{NT}$ & $20.77(15.58-27.66)$ \\
$\mathbf{1 4}$ & $33.17(26.92-40.89)$ & $\mathrm{NT}$ & $16.26(12.42-21.68)$ & $19.15(10.75-34.12)$ \\
$\mathbf{1 5}$ & $4.60(3.50-6.13)$ & $11.03(4.55-18.50)$ & $10.72(7.44-15.32)$ & $8.23(5.84-11.60)$ \\
$\mathbf{1 6}$ & $24.30(15.32-38.52)$ & $15.98(10.07-25.61)$ & $20.14(15.32-26.27)$ & $8.86(5.91-13.31)$ \\
Doxorubicin & $27.03(16.51-35.83)$ & $7.22(5.69-9.19)$ & $19.70(15.98-26.05)$ & $10.59(8.05-13.92)$ \\
\hline
\end{tabular}

aThe $50 \%$ inhibitory concentration $\left(\mathrm{IC}_{50}\right)$ values were calculated by non-linear regression with a confidence interval of $95 \%$. MCF-7: breast adenocarcinoma cell line; HCT-116: colon cancer cell line; NCI-H292: mucoepidermoid pulmonary carcinoma cell line; HL-60: promyelocytic leukemia cell line; NT: not tested.

Table 5. Cytotoxic activity against human PBMC and calculated SI of the most active compounds

\begin{tabular}{lccccc}
\hline \multirow{2}{*}{ Compound } & $\left.\mathrm{IC}_{50}(\mathrm{PBMC}) /(\mu \mathrm{mol} \mathrm{L})^{-1}\right)$ & \multicolumn{3}{c}{ Selectivity index } \\
\cline { 3 - 6 } $\mathbf{5}$ & $>90.02$ & MCF-7 & HCT-116 & NCI-H292 & HL-60 \\
$\mathbf{1 1}$ & $40.89(23.52-71.03)$ & 1.13 & 4.38 & 1.89 & 6.10 \\
$\mathbf{1 3}$ & $>56.45$ & 1.70 & 2.29 & 3.07 & 8.08 \\
$\mathbf{1 4}$ & $>54.71$ & 11.89 & - & 3.47 & 2.95 \\
$\mathbf{1 5}$ & $>54.71$ & 2.25 & 5.00 & 5.10 & 6.65 \\
$\mathbf{1 6}$ & $>54.71$ & 1.88 & 3.42 & 2.72 & 6.17 \\
Doxorubicin & $1.4(0.90-2.60)$ & 3.78 & 7.58 & 2.78 & 5.17 \\
\hline
\end{tabular}

$\mathrm{IC}_{50}: 50 \%$ inhibitory concentration values; MCF-7: breast adenocarcinoma cell line; HCT-116: colon cancer cell line; NCI-H292: mucoepidermoid pulmonary carcinoma cell line; HL-60: promyelocytic leukemia cell line; PBMC: peripheral blood mononuclear cells.

where the majority of the structures presented satisfactory results (SI $\geq 2.0$ ).

In general, the best selectivity results were observed in relation to the HL-60 cell line, whose SI values were greater than 5.0 for practically all tested molecules. It is also noteworthy that the acrylate $\mathbf{5}$ showed promising results against three of the four cell lines tested, creating perspectives for further studies of molecules endowed with Michael's accepting portion as anti-cancer agents.

All compounds evaluated here against the HCT- 116 cell line were more selective than doxorubicin, which presented $\mathrm{SI}=1.16$, whereas the minimum selectivity obtained for the synthesized compounds was 2.29 (compound 11).

The results of cytotoxic activity against human healthy cells reinforces the antiproliferative potential of the compound 14, which has the best calculated SI (11.89) in comparison to the others MBHA tested. Furthermore, adduct $\mathbf{1 4}$ was about three times more selective than doxorubicin.

\section{Conclusions}

In this paper, we present the convenient synthesis of a series of novel 7-chloroquinoline derivatives that were designed, synthesized in acceptable to good yields and well confirmed by FTIR, ${ }^{1} \mathrm{H}$ NMR, ${ }^{13} \mathrm{C}$ NMR and HRMS. The drug-likeness study showed promising scores for the new compounds, which were active against the cancer cell lines studied, with low levels of toxicity and considerable selectivity in comparison to the reference drug. We can highlight compound $\mathbf{1 4}$ that showed the best results for the four cancer cell lines and for SI, thus demonstrating the relevance of the application of 7-chloroquinoline in MBHR to obtain new anticancer compounds. 


\section{Supplementary Information}

Supplementary information is available free of charge at http://jbcs.sbq.org.br as PDF file.

\section{Acknowledgments}

The authors are grateful to the Conselho Nacional de Desenvolvimento Científico e Tecnológico (CNPQ), Coordenação de Aperfeiçoamento de Pessoal de Nível Superior (CAPES), Fundação de Amparo à Ciência e Tecnologia do Estado de Pernambuco (FACEPE) and Universidade Federal de Pernambuco (PROPESQ-UFPE).

\section{Author Contributions}

J.P.G.O., M.C.C. and A.C.C. conceptualized the experiment and wrote the paper; R.K.S.M., T.R.O., E.P.S., J.L.C.S. and S.M.S. conducted the experimental investigation; G.S.C. proposed the methodology adopted; B.G.V. and R.R.F.R. performed the formal analysis of data; M.L.A.A.V., C.G.L.J. and G.C.G.M. managed and coordinated the planning and execution of the study.

\section{References}

1. http://www.who.int/cancer/en/, accessed in September 2020.

2. https://www.inca.gov.br/o-que-e-cancer, accessed in September 2020.

3. Siegel, R. L.; Miller, K. D.; Jemal, A.; Ca-Cancer J. Clin. 2019, $69,7$.

4. Saraiva, M. T.; Krüger, R.; Baldinotti, R. S. M.; Lenardão, E. J.; Luchese, C.; Savegnago, L.; Wilhelm, E. A.; Alves, D.; J. Braz. Chem. Soc. 2016, 27, 41.

5. Fiorot, R.; Westphal, R.; Lemos, B. C.; Romagna, R. A.; Gonçalves, P. R.; Fernandes, M. R. N.; Ferreira, C. V.; Taranto, A. G.; Greco, S. J.; J. Braz. Chem. Soc. 2019, 30, 1860.

6. Bispo, M. D. L. F.; de Alcantara, C. C.; de Moraes, M. O.; do Ó Pessoa, C.; Rodrigues, F. R.; Kaiser, C. R.; Wardell, S. M. S. V.; Wardell, J. L.; de Souza, M. V. N.; Monatsh. Chem. 2015, 146, 2041.

7. Parhizgar, A. R.; Iran. J. Med. Sci. 2017, 42, 115.

8. Coimbra, E. S.; Antinarelli, L. M. R.; Silva, N. P.; Souza, I. O.; Meinel, R. S.; Rocha, M. N.; Soares, R. P. P.; da Silva, A. D.; Chem.-Biol. Interact. 2016, 260, 50.

9. Savegnago, L.; Vieira, A. I.; Seus, N.; Goldani, B. S.; Castro, M. R.; Lenardão, E. J.; Alves, D.; Tetrahedron Lett. 2013, 54, 40.

10. de Souza, M. V. N.; Pais, K. C.; Kaiser, C. R.; Peralta, M. A.; Ferreira, M. L.; Lourenço, M. C. S.; Bioorg. Med. Chem. 2009, 17,1474 .
11. Barbosa-Lima, G.; da Silveira Pinto, L. S.; Kaiser, C. R.; Wardell, J. L.; de Freitas, C. S.; Vieira, Y. R.; Marttorelli, A.; Cerbino Neto, J.; Bozza, P. T.; Wardell, S. M. S. V.; de Souza, M. V. N.; Souza, T. M. L.; Eur. J. Med. Chem. 2017, 127, 434.

12. da Silva Caleffi, G.; de Oliveira, J. P. G.; da Paz Silva, E.; Olegário, T. R.; Mendes, R. K. S.; Lima-Junior, C. G.; Silva, F. P. L.; Martins, F. T.; Vasconcellos, M. L. A. A.; J. Mol. Struct. 2017, 1133, 358

13. Morita, K.; Suzuki, Z.; Hirose, H.; Bull. Chem. Soc. Jpn. 1968, 41, 2815.

14. Baylis, A.; Hillman, M.; Ger. Pat. 2,155,113, 1972.

15. Lima-Junior, C. G.; Faheina-Martins, G. V.; Bomfim, C. C. B.; Silva, E. P.; de Araújo, D. A. M.; Alencar Filho, E. B.; Vasconcellos, M. L. A. A.; Med. Chem. 2016, 12, 602.

16. Lima-Junior, C. G.; Vasconcellos, M. L. A. A.; Bioorg. Med. Chem. 2012, 20, 3954.

17. Basavaiah, D.; Reddy, B. S.; Badsara, S. S.; Chem. Rev. 2010 , $110,5447$.

18. Santos, M. S.; Coelho, F. G.; Lima-Junior, C.; Vasconcellos, M. L. A. A.; Curr. Org. Synth. 2015, 12, 830.

19. Brito, V. B. M.; Santos, G. F.; Silva, T. D. S.; Souza, J. L. C.; Militão, G. C. G.; Mol. Diversity 2020, 24, 265.

20. Natarajan, J. K.; Alumasa, J. N.; Yearick, K.; Ekoue-Kovi, K. A.; Casabianca, L. B.; de Dios, A. C.; Wolf, C.; Roepe, P. D.; J. Med. Chem. 2008, 51, 3466.

21. Butina, D.; Segall, M. D.; Frankcombe, K.; Drug Discovery Today 2002, 7, S83.

22. Lipinski, C. A.; Lombardo, F.; Dominy, B. W.; Feeney, P. J.; Adv. Drug Delivery Rev. 1997, 23, 3.

23. Veber, D. F.; Johnson, S. R.; Cheng, H.-Y.; Smith, B. R.; Ward, K. W.; Kopple, K. D.; J. Med. Chem. 2002, 45, 2615.

24. Sander, T.; Freyss, J.; von Korff, M.; Reich, J. R.; Rufener, C.; J. Chem. Inf. Model. 2009, 49, 232.

25. Daina, A.; Michielin, O.; Zoete, V.; Sci. Rep. 2017, 7, 42717.

26. Clark, D. E.; Future Med. Chem. 2011, 3, 469.

27. Ertl, P.; Rohde, B.; Selzer, P.; J. Med. Chem. 2000, 43, 3714.

28. Zhao, Y. H.; Abraham, M. H.; Le, J.; Hersey, A.; Luscombe, C. N.; Beck, G.; Sherborne, B.; Cooper, I.; Pharm. Res. 2002, 19, 1446.

29. Mendes, J. A.; Salustiano, E. J.; Pires, C. S.; Oliveira, T.; Barcellos, J. C. F.; Cifuentes, J. M. C.; Costa, P. R. R.; Rennó, M. N.; Buarque, C. D.; Bioorg. Chem. 2018, 80, 585.

30. Skehan, P.; Storeng, R.; Scudiero, D.; Monks, A.; Mcmahon, J.; Vistica, D.; Warren, J. T.; Bokesch, H.; Kenney, S.; Boyd, M. R.; J. Natl. Cancer Inst. 1990, 82, 1107.

31. Koch, A.; Tamez, P.; Pezzuto, J.; Soejarto, D.; J. Ethnopharmacol. 2005, 101, 95 .

Submitted: May 21, 2020

Published online: September 15, 2020 